\title{
Comparison between the Oral Glucose Tolerance Test and the Hba1c Assay for Detecting Impaired Glucose Regulation in Bahamian Adolescents
}

\author{
${ }^{1}$ Department of Family Medicine, Princess Margaret Hospital, Nassau, Bahamas \\ ${ }^{2}$ Director of Family Medicine Program, University of the West Indies/Princess Margaret Hospital, Nassau, Bahamas \\ ${ }^{3}$ Epidemiologist and Biostatistician, Lecturer, University of the West Indies, Nassau, Bahamas \\ ${ }^{4}$ Consultant Endocrinologist, Internal Medicine, Princess Margaret Hospital, Nassau, Bahamas \\ ${ }^{5}$ Senior Lecturer, Internal Medicine, University of the West Indies, Nassau, Bahamas \\ ${ }^{6}$ Consultant Nephrologist, Internal Medicine, Princess Margaret Hospital, Nassau, Bahamas \\ ${ }^{7}$ Associate Lecturer, Internal Medicine, University of the West Indies, Nassau, Bahamas
}

Keith Leon Rivers ${ }^{1 *}$, Cherilyn Hanna-Mahase ${ }^{2}$, Morton Anthony Frankson ${ }^{3}$, Sebastian Peter ${ }^{4,5}$ and Frederick Phillip Smith ${ }^{6,7}$

\begin{abstract}
Objective: To determine the best method for detecting Impaired Glucose Regulation (IGR) in adolescents from New Providence Island, Bahamas. IGR is defined by blood glucose levels that are higher than normal but below those of a person with diabetes.

Design and Methods: From Jan-March 2012, 873 adolescents (13-19 years old) were randomly selected from five different high schools in New Providence. Weight and height were measured and participants were screened for IGR using the hemoglobin A1c ( $\mathrm{HbA1c}$ ) test and a 2-hour oral glucose tolerance test (OGTT). T-test or chi-square test was used to determine significant associations between sex and outcome variables, and prevalence of glycemic status by BMI category. Linear regression was used to determine the relationship between OGTT results and BMI.

Results: Of the initial pool, 861 adolescents (98.6\%) completed the study. The OGTT demonstrated that $89.4 \%$ of these students had normal fasting glucose levels and $98.8 \%$ had normal 2-hour OGTT glucose levels. Eightyseven students ( 37 boys and 50 girls) had elevated fasting plasma glucose; however, 2 hours after the oral glucose load, only 9 students ( 2 boys and 7 girls) had blood glucose concentrations indicative of IGR. For the HbA1c test, $82.6 \%$ of the students had normal results, and $1.3 \%$ had diabetes. The HbA1c test revealed a higher percentage of students with IGR $(16.1 \%)$ than the OGTT $(1 \%)$.

Conclusions: The HbA1c test identified a greater percentage of adolescents as having IGR than did the OGTT. Due to the high discordance between the two tests, it is likely that an elevated HbA1c test may falsely classify adolescents as IGR if OGTT results and clinical signs (e.g., diabetic retinopathy and/or nephropathy) are not considered.
\end{abstract}

Keywords: Impaired glucose tolerance; Adolescents; Oral glucose tolerance test; Hemoglobin A1c; New Providence

\section{Background}

The Bahamas has one of the highest diabetes mortality rates of the Caribbean nations [1]. This is due in part to the rising obesity rate, which is a consequence of an increasingly sedentary lifestyle and poor nutritional choices [2]. Although national data show an increase in chronic non-communicable diseases such as diabetes and hypertension in adults [3], there exists a paucity of data involving impaired glucose regulation in the younger Bahamian population. Due to the rising prevalence of diabetes among younger people, detecting and treating this disorder as early as possible has become a top public health priority. Healthcare expenditures consume almost $15 \%$ of the annual national budget, and a significant portion of this sum is spent on diabetes care [4]. Therefore, preventing this disorder can significantly decrease healthcare costs in the Bahamas.

Traditionally, Fasting Plasma Glucose (FPG) measurement and the Oral Glucose Tolerance Test (OGTT) were the primary methods used in the Bahamas to diagnose abnormal glucose metabolism, which is defined as having blood glucose levels that are higher than normal but below those of a person with diabetes [5]. Recent clinical practice, however, has shifted towards increased use of hemoglobin Alc ( $\mathrm{HbAlc})$ assessments to diagnose impaired glucose regulation in at-risk Bahamian populations. This change was influenced by the 2009 recommendation of the International Expert Committee (IEC) on Diabetes for using $\mathrm{HbAlc}$ measurement to detect abnormal glucose metabolism [6].

According to the World Health Organization (WHO) [7], an HbAlc cut-off point of $\geq 6.5 \%(47.5 \mathrm{mmol} / \mathrm{mol})$ is sufficient for diagnosing diabetes, and a level $\geq 6 \%(42.1 \mathrm{mmol} / \mathrm{mol})$ but $<6.5 \%$ $(47.5 \mathrm{mmol} / \mathrm{mol}) \mathrm{can}$ identify individuals at high risk for developing diabetes. Alternatively, the American Diabetes Association defines impaired glucose responsiveness (IGR) as an $\mathrm{HbA1c}$ level between

*Corresponding author: Keith Leon Rivers, Physician, Public Hospitals Authority, Family Medicine Department, 4th Terrace, Centerville, Nassau, New Providence N 3730, Bahamas, Tel: (242) 322-2861; E-mail: leonriv@yahoo.com

Received May 01, 2014; Accepted February 21, 2015; Published February 28, 2015

Citation: Rivers KL, Mahase CH, Frankson MA, Peter S, Smith FP (2015) Comparison between the Oral Glucose Tolerance Test and the Hba1c Assay for Detecting Impaired Glucose Regulation in Bahamian Adolescents. J Diabetes Metab 6: 511. doi:10.4172/2155-6156.1000511

Copyright: @ 2015 Rivers KL, et al. This is an open-access article distributed unde the terms of the Creative Commons Attribution License, which permits unrestricted use, distribution, and reproduction in any medium, provided the original author and source are credited. 
Citation: Rivers KL, Mahase CH, Frankson MA, Peter S, Smith FP (2015) Comparison between the Oral Glucose Tolerance Test and the Hba1c Assay for Detecting Impaired Glucose Regulation in Bahamian Adolescents. J Diabetes Metab 6: 511. doi:10.4172/2155-6156.1000511

Page 2 of 7

$5.7 \%$ and $6.4 \%$ [8], whereas the IEC defines IGR as an HbA1c level between $6.0 \%$ and $6.4 \%[6]$.

A cross-sectional study conducted in 2012 demonstrated that abnormal glucose regulation is positively associated with obesity in Bahamian adolescents [9]. Despite numerous studies having been performed on Bahamian adults, no studies have ascertained the clinical utility of the OGGT or HbAlc tests to diagnose IGR in Bahamian adolescents. Due to this knowledge gap, multiple tests are used to screen for abnormal glucose metabolism, including FPG, OGTT and HbAlc; however, no consensus has been established regarding the best approach to identify pre-diabetes in Bahamian adolescents. The main purpose of this study was to determine the most appropriate test for early IGR detection in Bahamian adolescents, using a cohort of apparently healthy adolescents without clinical symptoms. Adolescents categorized by body mass index (BMI) were assessed for IGR using both the OGTT and the HbAlc tests.

\section{Methods}

Permission to conduct this study was granted by the Ministry of Education, the combined Ethics Committee of the University of the West Indies and the Public Hospitals Authority, and by the Ministry of Health National Ethics Committee. Written informed consent was provided by parents/legal guardians, as well as assent by the participants. The study adhered to the tenets of the Declaration of Helsinki. This school-based study was conducted during the first academic quarter of 2012 (Jan-March), and initially included 873 adolescents (of which 861 completed the study) from five different public high schools on the island of New Providence, Bahamas.

\section{Sampling method}

A multi-stage sampling procedure using a mixture of both simple random sampling and stratified random methods ensured a sufficient number of students in each BMI category. First, simple random sampling was used to sample five of the eight high schools in New Providence. Six classes from each grade level (i.e., grades 10, 11, and 12) were randomly selected from each of the schools (for a total of 18 classes from each school and a grand total of 90 classes for the entire population). An initial written screening application was distributed to all students in the selected classes. Anthropometric information from the application was used to create five stratified BMI categories (underweight, normal, overweight, obese, and severely obese). Volunteers were randomly selected from the first each strata. A total of 2,671 students were in the 90 classes. Sample size was calculated based on the Bahamas Living Conditions Survey [10] (which outlines prevalence of obesity by age) to determine the appropriate number of subjects to randomly select from these BMI strat.

\section{Selection criteria}

We included any high school adolescent between the ages of 13 and 19 years with parental/guardian consent, and excluded students with previously diagnosed diabetes or thyroid disease, or who were using any potentially glucose level-altering drugs (e.g., prednisone for treating asthma).

\section{Anthropometric data collection}

Prior to enrollment, primary study foci and intentions were explained to prospective participants during school assemblies. The day before data collection, all study volunteers were reminded to fast overnight before testing. Each participant's weight $( \pm 0.1 \mathrm{~kg})$ and height $( \pm 0.1 \mathrm{~cm})$ were measured and the results were used to calculate
BMI as (weight in $\mathrm{kg} /$ height in $\mathrm{m}^{2}$ ). Subject BMI was classified using the 1995 WHO Expert Committee on Physical Status guidelines. Specifically: underweight $\left(\mathrm{BMI}<5^{\text {th }}\right.$ percentile), normal (BMI $5^{\text {th }}-84^{\text {th }}$ percentiles), overweight (BMI $85^{\text {th }}-94^{\text {th }}$ percentiles), obese (BMI $95^{\text {th }}$ $98^{\text {th }}$ percentiles), and severely obese (BMI $>99^{\text {th }}$ percentile) [11].

\section{Sample collection and analysis}

Venous blood samples were collected to measure glucose and $\mathrm{HbAlc}$ levels. Blood samples were collected at 0 hours for the FPG, HbA1c, and pre-glucose load OGTT measurements. After obtaining 0-hour blood samples, participants were orally administered a glucose solution $(1.75$ $\mathrm{g} / \mathrm{kg}$, maximum $100 \mathrm{~g}$ ) over a period of 5 minutes for the OGTT, and blood was collected 2 hours later. Blood samples for glucose analysis were collected in tubes containing sodium fluoride (anti-glycolytic stabilizer), and blood samples for determining $\mathrm{HbAlc}$ concentration were collected in tubes containing ethylenediaminetetraacetic acid (EDTA; anticoagulant).

Samples were transported on ice to the Princess Margaret Hospital Laboratory Services Department, New Providence Island, Bahamas. Whole blood for glucose testing was centrifuged and plasma separated from the cell fraction was refrigerated at $2-8^{\circ} \mathrm{C}$ and analyzed for plasma glucose within 24 hours. Samples for $\mathrm{HbAlc}$ testing were stored at $2-8^{\circ} \mathrm{C}$ and analyzed within 1 week. Additionally, calibrators were included for each assay in order to guarantee internal quality of the analyses. Samples were analyzed using a Dimension RXL chemistry analyzer (Siemens AG, Munich, Germany).

\section{Definition of abnormal glucose regulation}

Our study used the more conservative definition of the IEC to classify adolescents with IGR using $\mathrm{HbAlc}$ results. The WHO guidelines [12] define IGR based on OGTT as a 2-hour post-load blood glucose value $\geq 140 \mathrm{mg} / \mathrm{dl}(7.8 \mathrm{mmol} / \mathrm{l})$ but $<200 \mathrm{mg} / \mathrm{dl}(11.1 \mathrm{mmol} / \mathrm{l})$, and values $\geq 200 \mathrm{mg} / \mathrm{dl}$ as indicative of diabetes.

\section{Statistical analysis}

Glucose and HbAlc concentration data are represented as means \pm standard deviations (SDs). The chi-squared test was used to evaluate significance between two categorical variables and Student's t-test was used to assess continuous variables. Linear regression analysis was used to determine the relationship between OGTT results and BMI. The alpha level was set at 0.05 for all tests of statistical significance. Statistical Package for the Social Sciences software (SPSS v.19.0; IBM/ SPSS Inc., Chicago, IL, USA) was used to perform all calculations.

\section{Results}

Of the initial pool of 873 participants, 861 adolescents (98.6\%) completed the study. Six participants did not return to complete the OGTT, insufficient blood sample was collected from three persons, two participants refused a second phlebotomy because of pain, and one person did not complete consumption of the glucose solution within the required time frame of five minutes. Baseline demographics and anthropomorphic characteristics of the study population $(\mathrm{N}=861$ students) are respectively shown in Tables 1 and 2. Mean participant age was $15.82 \pm 1.11$ years (range 13-19 years). In terms of ethnicity, the predominant race was Black/Afro-Caribbean (98.8\%). Anthropometric data revealed a mean height of $174.16 \pm 7.64 \mathrm{~cm}$ (males) and 164.00 $\pm 6.21 \mathrm{~cm}$ (females) and a mean weight of $73.54 \pm 20.01 \mathrm{~kg}$ (males) and $67.06 \pm 18.73 \mathrm{~kg}$ (females). Glycemic status based on HbA1c and OGTT tests are presented in Table 3. Results showed that $98.8 \%$ of participants had a normal 2-hour OGTT level. A total of 87 students 
Citation: Rivers KL, Mahase CH, Frankson MA, Peter S, Smith FP (2015) Comparison between the Oral Glucose Tolerance Test and the Hba1c Assay for Detecting Impaired Glucose Regulation in Bahamian Adolescents. J Diabetes Metab 6: 511. doi:10.4172/2155-6156.1000511

\begin{tabular}{|l|c|c|c|}
\hline \multirow{2}{*}{ Variable } & Total Population & Male Students & Female Students \\
\cline { 2 - 4 } & $\mathbf{( N = 8 6 1 )}$ & $\begin{array}{c}\mathbf{( n = 2 7 2 )} \\
\mathbf{( n = 5 8 9 )}\end{array}$ & $15.78 \pm 1.10$ \\
\hline Age, yrs, mean \pm SD & $15.82 \pm 1.11$ & $15.88 \pm 1.13$ & $2(0.3)$ \\
\hline Age, $\mathrm{n}(\%)$ & & & $75(12.7)$ \\
\hline 13 yrs old & $2(0.2)$ & $0(0.0)$ & $161(27.3)$ \\
\hline 14 yrs old & $106(12.3)$ & $31(11.4)$ & $198(33.6)$ \\
\hline 15 yrs old & $238(27.6)$ & $77(28.3)$ & $123(20.9)$ \\
\hline 16 yrs old & $277(32.2)$ & $79(29.0)$ & $27(4.6)$ \\
\hline 17 yrs old & $189(22.0)$ & $66(24.3)$ & $3(0.5)$ \\
\hline 18 yrs old & $45(5.2)$ & $18(6.6)$ & $3(0.5)$ \\
\hline 19 yrs old & $4(0.5)$ & $1(0.4)$ & $584(99.2)$ \\
\hline Ethnicity, $n$ (\%) & $4(0.5)$ & $1(0.4)$ & $2(0.3)$ \\
\hline White/Caucasian & $851(98.8)$ & $267(98.2)$ & $0(0.0)$ \\
\hline Black/African American & $4(0.5)$ & $2(0.7)$ & \\
\hline $\begin{array}{l}\text { Asian and Pacific } \\
\text { Islanders }\end{array}$ & $2(0.2)$ & $2(0.7)$ & \\
\hline Latino/Hispanic & & & \\
\hline
\end{tabular}

Table 1: Demographics characteristics of the population.

\begin{tabular}{|c|c|c|c|}
\hline Variable & $\begin{array}{c}\text { Total } \\
\text { Population } \\
(\mathrm{N}=861)\end{array}$ & $\begin{array}{l}\text { Male Students } \\
\quad(n=272)\end{array}$ & $\begin{array}{l}\text { Female Students } \\
\qquad(\mathrm{n}=589)\end{array}$ \\
\hline Height, $\mathrm{cm}$, mean $\pm \mathrm{SD}$ & $167.21 \pm 8.19$ & $174.16 \pm 7.64$ & $164.00 \pm 6.21$ \\
\hline Weight, kg, mean \pm SD & $69.11 \pm 19.37$ & $73.54 \pm 20.01$ & $67.06 \pm 18.73$ \\
\hline $\mathrm{WC}, \mathrm{cm}$, mean $\pm \mathrm{SD}$ & $77.31 \pm 13.31$ & $83.55 \pm 13.73$ & $74.43 \pm 12.08$ \\
\hline $\mathrm{HC}, \mathrm{cm}$, mean $\pm \mathrm{SD}$ & $98.27 \pm 13.31$ & $99.36 \pm 13.14$ & $97.76 \pm 13.37$ \\
\hline $\mathrm{BMI}, \mathrm{kg} / \mathrm{m}^{2}$, mean $\pm \mathrm{SD}$ & $24.71 \pm 6.75$ & $24.21 \pm 6.44$ & $24.94 \pm 6.88$ \\
\hline WHR, mean $\pm S D$ & $0.79 \pm 0.07$ & $0.84 \pm 0.06$ & $0.76 \pm 0.05$ \\
\hline WHtR, mean $\pm \mathrm{SD}$ & $0.46 \pm 0.08$ & $0.48 \pm 0.08$ & $0.45 \pm 0.07$ \\
\hline \multicolumn{4}{|c|}{ Weight Status based on BMI } \\
\hline Underweight, n (\%) & $19(2.2)$ & $3(1.1)$ & $16(2.7)$ \\
\hline Normal, n (\%) & $514(59.7)$ & $179(65.8)$ & 335 (56.9) \\
\hline Overweight, n (\%) & $129(15.0)$ & $33(12.1)$ & $96(16.3)$ \\
\hline Obese, n (\%) & $131(15.2)$ & $27(9.9)$ & $104(17.7)$ \\
\hline Severely obese, n (\%) & $68(7.9)$ & $30(11)$ & $38(6.5)$ \\
\hline \multicolumn{4}{|l|}{ Weight Status based on WC } \\
\hline Normal, n (\%) & 783 (90.9) & $222(81.6)$ & $561(95.2)$ \\
\hline Central obese, n (\%) & $78(9.1)$ & $50(18.4)$ & $28(4.8)$ \\
\hline \multicolumn{4}{|c|}{ Weight Status based on WHtR } \\
\hline Normal, n (\%) & $643(74.7)$ & $194(71.3)$ & 449 (76.2) \\
\hline Central obese, n (\%) & $218(25.3)$ & $78(28.7)$ & $140(23.8)$ \\
\hline
\end{tabular}

Note. WC, Waist Circumference; HC, Hip Circumference; WHR, Waist-hip ratio; WHtR, Waist-to-Height Ratio.

Table 2: Summary of anthropometric characteristics.

(37 boys and 50 girls) showed elevated FPG concentrations, indicative of IFG. However, 2 hours after the oral glucose load, only 9 students $(2$ boys and 7 girls) had blood glucose concentrations in the IGR range.

Of the 861 participants, 710 students $(82.5 \%)$ were defined as glucose-normal with both the OGTT 2-hour glucose level and HbAlc assays. The remaining 151 students were diagnosed as either IGR or Diabetic by at least one of the two tests. In particular, 39 participants were defined as IGR and 11 as diabetic by HbAlc test and 9 were identified as IGR and 1 as diabetic by OGTT. Figure 1 shows the assessment based on individual OGTT 2 hour glucose levels and $\mathrm{HbAlc}$ values, with color bands delineating IGR and diabetes diagnoses. Most of the students (82.6\%) had normal HbAlc test results (Table 3). The HbA1c test revealed a higher percentage of students with IGR (16.1\%) than the OGTT (1.0\%). There was a significant difference between male and female students in assessing IGR based on HbAlc $\left[X^{2}(2, \mathrm{~N}=861)=8.75, \mathrm{p}=0.013\right]$. However, there was no significant difference between gender groups based on the OGTT.

The prevalence of glycemic status by BMI category is shown in Table 4 . Based on HbAlc test results, $17.8 \%$ of overweight adolescents had IGR compared with $6.2 \%$ of normal-weight youths, and IGR was much more prevalent among obese (35.1\%) and severely obese $(55.9 \%)$ adolescents. Similarly, despite the lower frequency, the IGR prevalence based on OGTT results was higher with increasing BMI status.

To assess the association between the OGTT 2-hour glucose level and obesity predictors, linear regression analyses were separately performed for male and female student groups. Model diagnostics were performed to ensure that the assumptions had been met. Stepwise linear regression models were fitted using BMI as the predictor variable, and demonstrated that BMI was significantly associated with the OGTT 2-hour post-load glucose level for both males and females (Table 5). In particular, for every one-unit increase in BMI, there was a corresponding respective $1.5 \%$ or $1.3 \%$ increase in the OGTT 2-hour glucose level for males or females (as demonstrated by the $\beta$-coefficients).

\section{Discussion}

Type-2 diabetes represents a significant burden on the healthcare system of the Bahamas. Thus, there is a profound need for early detection of the silent metabolic disorders that precede progression to active diabetes. Test accuracy is the most important factor in selecting an IGR screening test; the method that yields the highest specificity and sensitivity should be the preferred modality for detecting intermediate

\begin{tabular}{|c|c|c|c|c|c|}
\hline Variable & $\begin{array}{c}\text { Total } \\
\text { Population } \\
(\mathbf{N}=\mathbf{8 6 1})\end{array}$ & $\begin{array}{c}\text { Male } \\
\text { Students } \\
(\mathrm{n}=272)\end{array}$ & $\begin{array}{l}\text { Female } \\
\text { Students } \\
(n=589)\end{array}$ & $\begin{array}{c}\mathbf{p} \\
\text { Valuet }\end{array}$ & $\begin{array}{l}\text { Effect } \\
\text { Sizet† }\end{array}$ \\
\hline $\begin{array}{l}\text { FPG, mg/dl, mean } \\
\pm \text { SD }\end{array}$ & $\begin{array}{c}88.3 \pm \\
10.25\end{array}$ & $\begin{array}{c}88.95 \pm \\
10.7\end{array}$ & $88 \pm 10.03$ & 0.202 & 0.092 \\
\hline $\begin{array}{l}\text { OGTT 2-hour glucose } \\
\text { level, mg/dl, mean } \\
\pm \text { SD }\end{array}$ & $\begin{array}{c}88.37 \pm \\
17.76\end{array}$ & $\begin{array}{c}88.19 \pm \\
14.74\end{array}$ & $88.46 \pm 19$ & 0.401 & -0.016 \\
\hline $\begin{array}{l}\mathrm{HbA} 1 \mathrm{c}(\%), \% \text { of } \mathrm{Hb} \\
\text { (mmol/L value), mean } \\
\pm \mathrm{SD}\end{array}$ & $\begin{array}{c}5.6 \pm \\
0.41(37.7)\end{array}$ & $\begin{array}{c}5.58 \pm 0.42 \\
(39.9)\end{array}$ & $\begin{array}{c}5.61 \pm 0.4 \\
(37.8)\end{array}$ & 0.821 & -0.073 \\
\hline $\begin{array}{l}\text { Assessment based } \\
\text { on FPG }\end{array}$ & & & & 0.067 & 0.079 \\
\hline Normal, n (\%) & 770 (89.4) & $234(86.0)$ & $536(91.0)$ & & \\
\hline IFG, n (\%) & $87(10.1)$ & $37(13.6)$ & $50(8.5)$ & & \\
\hline Diabetes, n (\%) & $4(0.5)$ & $1(0.4)$ & $3(0.5)$ & & \\
\hline \multicolumn{4}{|c|}{ Assessment based on OGTT 2-hour glucose level } & 0.659 & 0.031 \\
\hline Normal, n (\%) & $851(98.8)$ & $270(99.3)$ & $581(98.6)$ & & \\
\hline IGR, n (\%) & $9(1.0)$ & $2(0.7)$ & $7(1.2)$ & & \\
\hline Diabetes, n (\%) & $1(0.1)$ & $0(0.0)$ & $1(0.2)$ & & \\
\hline \multicolumn{4}{|c|}{ Assessment based on $\mathrm{HbA} 1 \mathrm{c}$} & 0.013 & 0.101 \\
\hline Normal, n (\%) & 711 (82.6) & $218(80.1)$ & $493(83.7)$ & & \\
\hline IGR, n (\%) & $139(16.1)$ & $54(19.9)$ & $85(14.4)$ & & \\
\hline Diabetes, n (\%) & $11(1.3)$ & $0(0.0)$ & $11(1.9)$ & & \\
\hline
\end{tabular}

Note. FPG, fasting plasma glucose; OGTT, oral glucose tolerance test; IGR impaired glucose regulation. †Two-sided independent t-test (continuous variables) or chi-square test (categorical variable) to determine the association between sex and each variable. Bold font indicates statistical significance at the 0.05 level. †† Effect size indicates strength of relationship between variables.

Table 3: Summary of FPG, OGTT 2-hour post-load glucose level, and HbA1c results, and IGR and diabetes assessments based on those results. 
Citation: Rivers KL, Mahase CH, Frankson MA, Peter S, Smith FP (2015) Comparison between the Oral Glucose Tolerance Test and the Hba1c Assay for Detecting Impaired Glucose Regulation in Bahamian Adolescents. J Diabetes Metab 6: 511. doi:10.4172/2155-6156.1000511

Page 4 of 7
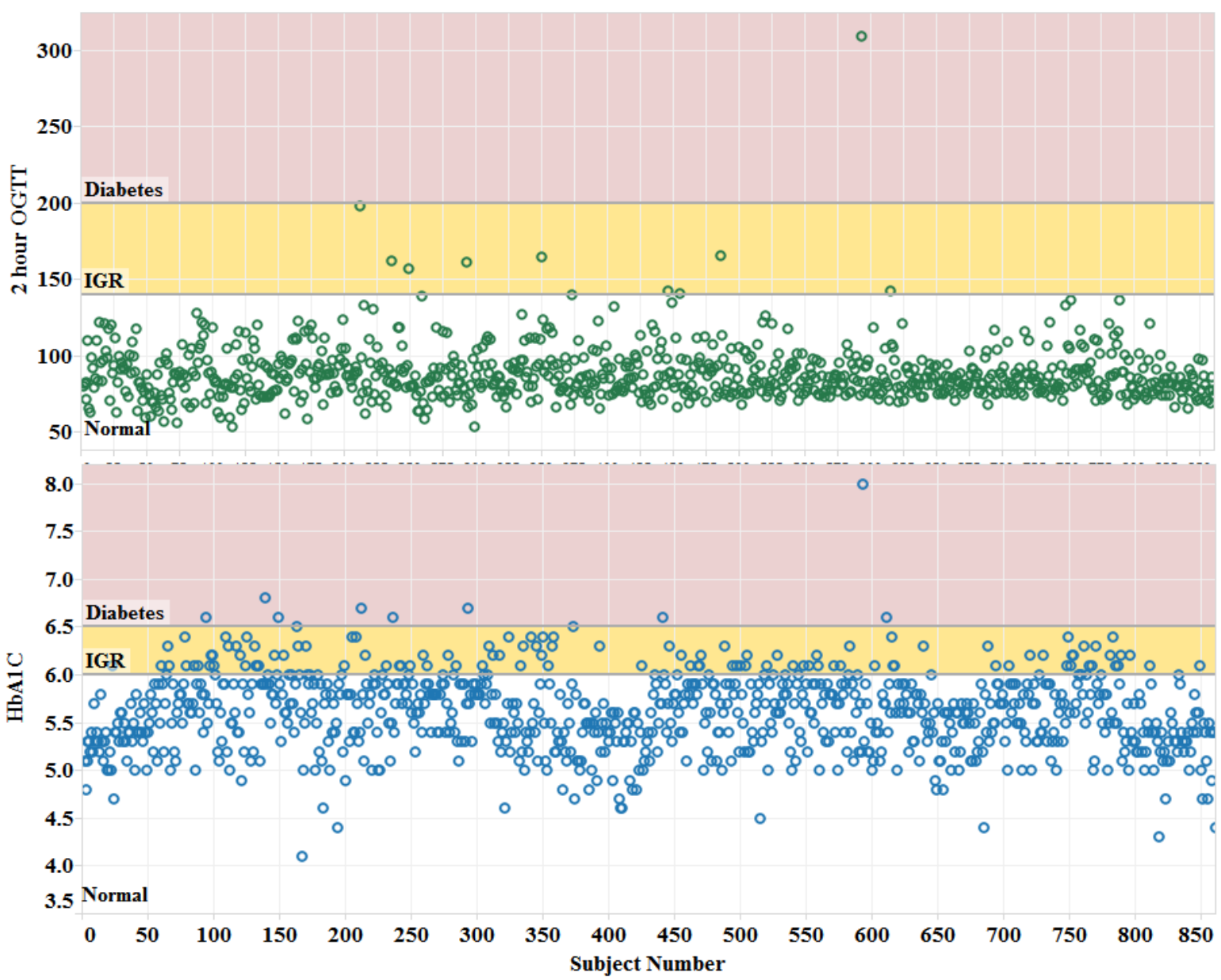

Figure 1: Diabetic status assessment using OGTT 2-hour glucose level and $\mathrm{HbA1c}$ values. The X-axis represents the individual subjects and the $\mathrm{Y}$-axis represents the 2 hour OGTT level (green circles) and $\mathrm{HbA1C}$ level (blue circles) for each subject. The assessments are shown in different color bands signifying normal (white region), IGR (orange region), and diabetic (lavender region) values for each assay.

\begin{tabular}{|c|c|c|c|c|c|c|c|c|c|}
\hline \multirow{2}{*}{ BMI Category } & \multicolumn{3}{|c|}{ Total Population ( $\mathrm{N}=\mathbf{8 6 1})$} & \multicolumn{3}{|c|}{ Male Students $(n=272)$} & \multicolumn{3}{|c|}{ Female Students $(n=589)$} \\
\hline & Normal & IGR & Diabetes & Normal & IGR & Diabetes & Normal & IGR & Diabetes \\
\hline \multicolumn{10}{|c|}{ Assessment by HbA1c, $\mathrm{n}(\%)$} \\
\hline Underweight & $19(100.0)$ & $0(0.0)$ & $0(0.0)$ & $3(100.0)$ & $0(0.0)$ & $0(0.0)$ & $16(100.0)$ & $0(0.0)$ & $0(0.0)$ \\
\hline Normal & $481(93.6)$ & $32(6.2)$ & $1(0.2)$ & $166(92.7)$ & $13(7.3)$ & $0(0.0)$ & $315(94.0)$ & $19(5.7)$ & $1(0.3)$ \\
\hline Overweight & $106(82.2)$ & $23(17.8)$ & $0(0.0)$ & $25(75.8)$ & $8(24.2)$ & $0(0.0)$ & $81(84.4)$ & $15(15.6)$ & $0(0.0)$ \\
\hline Obese & $82(62.6)$ & $46(35.1)$ & $3(2.3)$ & $14(51.9)$ & $13(48.1)$ & $0(0.0)$ & $68(65.4)$ & $33(31.7)$ & $3(2.9)$ \\
\hline Severely obese & $23(33.8)$ & $38(55.9)$ & $7(10.3)$ & $10(33.3)$ & $20(66.7)$ & $0(0.0)$ & $13(34.2)$ & $18(47.4)$ & $7(18.4)$ \\
\hline \multicolumn{10}{|c|}{ Assessment by OGTT 2-hour post-load glucose level, n (\%) } \\
\hline Underweight & $19(100.0)$ & $0(0.0)$ & $0(0.0)$ & $3(100.0)$ & $0(0.0)$ & $0(0.0)$ & $16(100.0)$ & $0(0.0)$ & $0(0.0)$ \\
\hline Normal & $512(99.6)$ & $2(0.4)$ & $0(0.0)$ & $179(100.0)$ & $0(0.0)$ & $0(0.0)$ & $333(99.4)$ & $2(0.6)$ & $0(0.0)$ \\
\hline Overweight & $129(100.0)$ & $0(0.0)$ & $0(0.0)$ & $33(100.0)$ & $0(0.0)$ & $0(0.0)$ & $96(100.0)$ & $0(0.0)$ & $0(0.0)$ \\
\hline Obese & $129(98.5)$ & $2(1.5)$ & $0(0.0)$ & $27(100.0)$ & $0(0.0)$ & $0(0.0)$ & $102(98.1)$ & $2(1.9)$ & $0(0.0)$ \\
\hline Severely obese & $62(91.2)$ & $5(7.4)$ & $1(1.5)$ & $28(93.3)$ & $2(6.7)$ & $0(0.0)$ & $34(89.5)$ & $3(7.9)$ & $1(2.6)$ \\
\hline
\end{tabular}

Table 4: Glycemic status by BMI category.

hyperglycemia. Two different methods-the OGTT and the HbAlc test-were used to assess glycemic status in this study.

A greater proportion of the adolescents sampled were diagnosed with IGR when using the HbA1c test compared to the OGTT. Nine students (1.0\% prevalence) were diagnosed with IGR based on OGTT results, and 139 students (16.1\%) were diagnosed with IGR based on HbAlc values. These results reveal a marked discordance between the two tests in identifying individuals with IGR. There are several possible explanations for this discrepancy. First, research has suggested that the HbAlc test is more accurate than the OGTT [13-15]. Farhan et al. noted that the two tests differ significantly in their ability to detect individuals who are at risk of developing type-2 diabetes, [13] with IGR diagnosed in $45.6 \%$ of patients based on the $\mathrm{HbA} 1 \mathrm{c}$ test compared with $21.6 \%$ of patients based on the OGTT. Raman and Maitra reported that 
Citation: Rivers KL, Mahase CH, Frankson MA, Peter S, Smith FP (2015) Comparison between the Oral Glucose Tolerance Test and the Hba1c Assay for Detecting Impaired Glucose Regulation in Bahamian Adolescents. J Diabetes Metab 6: 511. doi:10.4172/2155-6156.1000511

Page 5 of 7

\begin{tabular}{|c|c|c|c|}
\hline & В & SE & $\boldsymbol{P}$ \\
\hline \multicolumn{4}{|c|}{$\begin{array}{l}\text { Males (N=272) } \\
\text { Ln(OGTT 2-hour post-load glucose leve }\end{array}$} \\
\hline Intercept & 4.098 & 0.029 & $<0.001$ \\
\hline BMI & 0.015 & 0.001 & $<0.001$ \\
\hline \multicolumn{4}{|c|}{ Females $(\mathrm{N}=589)$} \\
\hline \multicolumn{4}{|c|}{ Ln(OGTT 2-hour post-load glucose level) ${ }^{b}$} \\
\hline Intercept & 4.136 & 0.025 & $<0.001$ \\
\hline BMI & 0.013 & 0.001 & $<0.001$ \\
\hline
\end{tabular}

Note. ${ }^{a} R^{2}=0.397,{ }^{b} R^{2}=0.248 . S E$, Standard Error

Table 5: Linear regression models of OGTT 2-hour post-load glucose level and BMI.

the HbAlc test was almost three-times more likely to detect diabetes than the OGTT [14]. Additionally, Borg et al found that the OGTT and the $\mathrm{HbAlc}$ test were unable to classify the same individuals as having diabetes, and noted uncertainty as to whether the two tests can equally recognize persons who are at risk of developing diabetic complications [16]. Similarly, Tsay et al. retrospectively examined various IGR predictors in obese adolescents, including ethnicity, stage of puberty, BMI, blood pressure, lipid levels, HbA1c, and OGTT results. Of these parameters, HbAlc was the only significant predictor of IGR [15].

In contrast to the previous observations comparing $\mathrm{HbAlc}$ vs OGTT assays, some researchers argue that FPG levels are more reliable than $\mathrm{HbAlc}$ when evaluating individuals for IGR. For example, Mann et al examined data from the National Health and Nutrition Survey 1999-2006 and found that more pre-diabetic patients were inappropriately diagnosed as normal using the $\mathrm{HbAlC}$ test than by FPG levels [17]. Additionally, Picon et al. observed that the HbAlc test (19.05\%) identified fewer individuals with gestational diabetes mellitus than the OGTT (45.89\%) [18]. Finally, some authors have suggested that adult $\mathrm{HbAlc}$ thresholds may be too high for accurately diagnosing IGR in younger individuals [19].

Although the marked discrepancy in the HbAlc vs OGTT results of this study is difficult to reconcile with the available data, it is unlikely caused by laboratory error because strict quality control guidelines were used to ensure accuracy of the results. Moreover, unlike the Diabetes Control and Complications Trial (DCCT) which used HighPerformance Liquid Chromatography (HPLC) to measure HbAlc levels, the present study employed a direct enzymatic assay method that has greater specificity and precision, and is more appropriate for use with modern chemistry analyzers [20]. In addition, the enzymatic method is faster, simpler, and much cheaper than HPLC [20]. The $\mathrm{HbA1c}$ test results of the present study can be confidently compared to the results of the DCCT, because they have been standardized according to the National Glycohemoglobin Standardization Program and the International Federation of Clinical Chemistry and Laboratory Medicine Working Group on Standardization of HbAlc [21].

Several other possibilities must be considered to explain the incongruity between the numbers of IGR cases identified by the HbAlc assay versus the OGTT. The ethnic profile of the population sampled may have been a factor, because previous studies have shown that youths of African descent have consistently higher HbAlc values than youths of other racial backgrounds [22,23]. Saadine et al. looked at $\mathrm{HbA1c}$ levels of healthy individuals between the ages of 5 and 24 years [23]; after adjusting for age, sex, education level, weight status, and fasting plasma glucose, non-Hispanic black youths had HbAlc values above those of non-Hispanic whites and Mexican-Americans. This observation may be useful in clinical settings involving youths of African ancestry. Similarly, among individuals with type-1 diabetes,

adolescents had higher HbA1c levels than adults, even though they were treated with higher doses of insulin [24].

Another reason that dysglycemia was seen more often with the HbAlc test than with OGTT was probably due to the age of the participants. Significant fluctuations in $\mathrm{HbAlc}$ values occur during early adolescence, even among euglycemic individuals [25]. Hormonal changes and insulin insensitivity in this age group are the most likely contributing factors. A cross-sectional study by Moran et al demonstrated that insulin insensitivity is a common phenomenon during puberty, with peaks between ages 14 and 16 years [26]. Additionally, circulating levels of growth hormone, which antagonizes insulin $[27,28]$, are highest during puberty. Mean cohort age is probably one reason why the $\mathrm{HbAlc}$ appeared to overestimate the prevalence of IGR in the adolescents sampled in this research.

The HbAlc test was originally intended to detect abnormal glucose metabolism in adults [8], while the participants in the current research were exclusively adolescents. The HbAlc test has proven success in identifying adults with diabetes and IGR [29], but has not been shown to be as reliable when used to evaluate IGR in youths [30,31]. Saadine et al. evaluated data from NHANES III trial to establish national reference ranges for individuals between the ages of 5-24 years [23]. Even though there were slight differences across sex and racial groups, the differences were not great enough to warrant separate norms. Furthermore, Libman has also pointed out that both the pediatric and adult populations currently share the same criteria for diagnosing dysglycemia [32].

There is strong evidence for the presence of IGR in Bahamian youths [9], and it is therefore imperative to detect this disorder early in life to avoid further complications and morbidity. Our observations may serve as a stimulus to conduct prospective studies to determine whether Bahamian adolescents with high $\mathrm{HbA1c}$ values develop early type-2 diabetes, as has been reported in other populations [33]. This information may also indicate the need for further clinical evaluations to determine whether elevated HbAlc levels are associated with complications such as diabetic retinopathy or nephropathy [34,35], or if this is simply a normal genetic quality of this particular group. There are currently no specific reference ranges for $\mathrm{HbAlc}$ values in Bahamian adolescents. Therefore, these findings will also help to evaluate the need to conduct a nationally representative longitudinal study of Bahamian adolescents and pinpoint whether or not a unique HbAlc distribution profile exists in this population.

An important finding of this study is that the severely obese subjects had higher HbAlc and OGTT values than adolescents from the lower BMI categories. This group likely represents true IGR and therefore requires considerable intervention to prevent conversion to overt type2 diabetes. Both lifestyle modifications and therapeutic management have been shown to improve glycemic status in individuals with type2 diabetes [36]. In the current study, adolescents identified as IGR or diabetes were contacted and referred to the Family Medicine Center of the Princess Margaret Hospital for further evaluation of their condition. Identification of diabetes at-risk groups should promote efforts to raise awareness of adolescent pre-diabetes and solicit support from stakeholders such as the Bahamian Ministry of Education to develop better nutritional choices by school vendors and to establish appropriate extracurricular exercise activities.

One notable strength of this study is that it was conducted at several different sites, and the sample size needed to ensure appropriate statistical power of the study was easily achieved. A limitation of the 
Citation: Rivers KL, Mahase CH, Frankson MA, Peter S, Smith FP (2015) Comparison between the Oral Glucose Tolerance Test and the Hba1c Assay for Detecting Impaired Glucose Regulation in Bahamian Adolescents. J Diabetes Metab 6: 511. doi:10.4172/2155-6156.1000511

Page 6 of 7

present study is that participants were not screened to determine whether certain conditions known to interfere with accurate HbA1c measurement were present in the study population. Published literature indicates that HbAlc levels can be affected by kidney disease, liver disease, hemoglobin abnormalities, and vitamin deficiencies [37,38]. Another major limitation was that we did not measure plasma insulin levels in participants. Insulin analysis would have allowed performing homeostatic model assessments (HOMA) of pancreatic $\beta$-cell function (HOMA2-\%B) and insulin resistance (HOMA-IR) as covariates. This is a pioneer study which identified an association between IGR and obesity in Bahamian adolescents. Further study incorporating insulin levels, hemoglobin electrophoresis and kidney function test will be done in the future to identify potential confounders. The data in this research refers predominantly to black Bahamian adolescents from the island of New Providence. Therefore, our findings cannot be generalized to all ethnic groups or the entire nation, and these results need to be verified by testing a larger segment of the population.

In conclusion, an elevated HbA1c test may falsely classify Bahamian adolescents as IGR if OGTT results and clinical signs (e.g., diabetic retinopathy and/or nephropathy) are not considered. Bahamian adolescents showed a very weak correlation between the HbAlc assay and the OGTT, which should be appreciated when evaluating patients in this age group who display elevated $\mathrm{HbAlc}$ values. Clinicians should consider other possible reasons than dysglycemia as a cause of elevated $\mathrm{HbAlc} \mathrm{levels} \mathrm{when} \mathrm{assessing} \mathrm{these} \mathrm{young} \mathrm{patients.} \mathrm{Because} \mathrm{there} \mathrm{exists}$ very little published information about which method best detects IGR in Bahamian adolescents, the data from this and related future studies can be used to amend this current knowledge deficit.

\section{Acknowledgements}

Sincerest appreciation for our sponsors, the Public Hospitals Authority, Herbert Brown, Hannah Gray, Jackie Cleare, Michelle Taylor, Janet Hall; Diabetic Research Institute of The Bahamas, Harald McPike, Nassau Harbour Pilot Association, Sir Durward Knowles, the Cable Bahamas Cares Foundation, Atty Craig Butler, Golden Gates Clinic, Dr. Drexel Williams, Colina General Insurance Agency Ltd, Galleria Cinemas Ltd, Aetos Holdings Ltd, and Restaurant Bahamas Ltd. Heartfelt thanks to The Bahamas Min. of Education, PS Elma Garraway, superintendents, principals, teachers, guidance counselors, staff, and students of R.M. Bailey, C.V. Bethel, C.I. Gibson, C.C. Sweeting, and the Government High School; members of the research team including Dr. Catherine Conliffe, Kayla Ingraham, Selina Stuart, Genean Clear, Tania Roberts, Latoya Deveaux, Shezelle Rolle, and Richard Ojeabulu; the Princess Margaret Hospital Chemistry Laboratory Department, Gretchen Davis, Beverley Archer, Sybil Burrows, Karen Ingraham, Malriae Ferguson, and Jeffyvonne Sands. Special thanks to Dr. Hui Liu for additional statistical advice.

\section{References}

1. Ferguson TS, Tulloch-Reid MK, Wilks RJ (2010) The epidemiology of diabetes mellitus in Jamaica and the Caribbean: a historical review. West Indian Med $J$ 59: 259-264.

2. Food and Agriculture Organization of the United Nations (FAO) (2003). Nutrition Country Profile for The Bahamas.

3. Nixon C (2011) Obesity crisis for Bahamian children. The Tribune A:1.

4. The Government of the Bahamas. [Internet]. National Budgets Documents 2013

5. Gerstein HC, Santaguida P, Raina P, Morrison KM, Balion C, et al. (2007) Annual incidence and relative risk of diabetes in people with various categories of dysglycemia: a systematic overview and meta-analysis of prospective studies. Diabetes Res Clin Pract 78: 305-312.

6. International Expert Committee (2009) International Expert Committee report on the role of the A1C assay in the diagnosis of diabetes. Diabetes Care 32: 1327-1334.

7. WHO (2011) HbA1c in the diagnosis of type 2 diabetes: a systematic review. Abbreviated Report of a WHO Consultation. World Health Organization. Geneva.
8. American Diabetes Association (2014) Standards of medical care in diabetes--2014. Diabetes Care 37 Suppl 1: S14-80.

9. Rivers K, Hanna-Mahase C, Frankson M, Smith F, Peter S (2014) Association between Obesity and Impaired Glucose Tolerance in New Providence Adolescents as Demonstrated by the HbA1c Test. West Indian Med J 62: 705710

10. Department of Statistics (2004) Bahamas Living Conditions Survey 2001 Nassau, Bahamas.

11. (1995) Physical status: the use and interpretation of anthropometry. Report of a WHO Expert Committee. World Health Organ Tech Rep Ser 854: 1-452.

12. WHO (2006) Definition, diagnosis and classification of diabetes mellitus and its complications. Part 1: diagnosis and classification of diabetes mellitus. Provisional report of a WHO Consultation. Diabet Med 2006: 1-46.

13. Farhan S, Jarai R, Tentzeris I, Kautzky-Willer A, Samaha E, et al. (2012) Comparison of $\mathrm{HbA} 1 \mathrm{c}$ and oral glucose tolerance test for diagnosis of diabetes in patients with coronary artery disease. Clin Res Cardiol 101: 625-630.

14. Raman P, Maitra S (2000) A comparative study of oral glucose tolerance test and glycated haemoglobin in high risk patients for diabetes mellitus. Inter. J. Diab. Developing Countries 2000: 23-28.

15. Tsay J, Pomeranz C, Hassoun A, Zandieh S, Rutledge J, et al. (2010) Screening Markers of Impaired Glucose Tolerance in the Obese Pediatric Population. Horm Res Paediatr 73: 102-107.

16. Borg R, Vistisen D, Witte D, Borch-Johnsen K (2010) Comparing risk profiles of individuals diagnosed with diabetes by OGTT and HbA1cThe Danish Inter99 study. Diabet Med 27: 906-910.

17. Mann DM, Carson AP, Shimbo D, Fonseca V, Fox CS, et al. (2010) Impact of A1C screening criterion on the diagnosis of pre-diabetes among U.S. adults. Diabetes Care 33: 2190-2195.

18. Picon M, Murri M, Munoz A, Fernandez-Garcia J, Gomez-Huelgas R, et al (2012) Hemoglobin A1c Versus Oral Glucose Tolerance Test in Postpartum Diabetes Screening. Diabetes Care 35: 1648-1653.

19. Lee J, Wu E, Tarini B, Herman W, Yoon E (2011) Diagnosis of Diabetes using Hemoglobin A1c: Should Recommendations in Adults Be Extrapolated to Adolescents? J Pediatr 158: 947-952.

20. Liu L, Hood S, Wang Y, Bezverkov R, Dou C, et al. (2008) Direct enzymatic assay for \% HbA1c in human whole blood samples. Clin Biochem 41: 576-583.

21. Mostafa SA, Davies MJ, Srinivasan BT, Carey ME, Webb D, et al. (2010) Should glycated haemoglobin $(\mathrm{HbA} 1 \mathrm{c})$ be used to detect people with type 2 diabetes mellitus and impaired glucose regulation? Postgrad Med J 86: 656662.

22. Eldeirawi K (2003) Predictors of Hemoglobin A1c in a National Sample of Nondiabetic Children: The Third National Health and Nutrition Examination Survey, 1988-1994. American Journal of Epidemiology 157: 624-632.

23. Saaddine J, Fagot-Campagna A, Rolka D, Narayan K, Geiss L, et al. (2002) Distribution of HbA1c Levels For Children and Young Adults in the U.S.: Third National Health and Nutrition Examination Survey. Diabetes Care 25: 13261330.

24. (1994) Effect of intensive diabetes treatment on the development and progression of long-term complications in adolescents with insulin-dependent diabetes mellitus: Diabetes Control and Complications Trial. Diabetes Control and Complications Trial Research Group. J Pediatr 125: 177-188.

25. Hosking J, Metcalf B, Jeffery A, Streeter A, Voss L, et al. (2013) Divergence between $\mathrm{HbA} 1 \mathrm{c}$ and fasting glucose through childhood: implications for diagnosis of impaired fasting glucose (EarlyBird 52). Pediatric Diabetes 15: 214-219.

26. Moran A, Jacobs D, Steinberger J, Cohen P, Hong C, et al. (2002) Association between the Insulin Resistance of Puberty and the Insulin-Like Growth Factor-I/ Growth Hormone Axis. The Journal of Clinical Endocrinology \& Metabolism. 87: 4817-4820.

27. Amiel SA, Sherwin RS, Simonson DC, Lauritano AA, Tamborlane WV (1986) Impaired insulin action in puberty. A contributing factor to poor glycemic control in adolescents with diabetes. N Engl J Med 315: 215-219.

28. Arslanian S, Kalhan S (1994) Correlations Between Fatty Acid and Glucose Metabolism: Potential Explanation of Insulin Resistance of Puberty. Diabetes 43: $908-914$ 
Citation: Rivers KL, Mahase CH, Frankson MA, Peter S, Smith FP (2015) Comparison between the Oral Glucose Tolerance Test and the Hba1c Assay for Detecting Impaired Glucose Regulation in Bahamian Adolescents. J Diabetes Metab 6: 511. doi:10.4172/2155-6156.1000511

29. Sacks DB (2011) A1C versus glucose testing: a comparison. Diabetes Care 34: $518-523$

30. Lee J, Gebremariam A, Wu E, LaRose J, Gurney J (2011) Evaluation of Nonfasting Tests to Screen for Childhood and Adolescent Dysglycemia. Diabetes Care 34: 2597-2602.

31. Nowicka P, Santoro N, Liu H, Lartaud D, Shaw MM, et al. (2011) Utility of hemoglobin $\mathrm{A}(1 \mathrm{c})$ for diagnosing prediabetes and diabetes in obese children and adolescents. Diabetes Care 34: 1306-1311.

32. Libman IM, Arslanian SA (2007) Prevention and treatment of type 2 diabetes in youth. Horm Res 67: 22-34.

33. Weiss R, Taksali SE, Tamborlane WV, Burgert TS, Savoye M, et al. (2005) Predictors of changes in glucose tolerance status in obese youth. Diabetes Care 28: 902-909.

34. McCane D, Hanson R, Charles M, Jacobsson L, Pettitt D, et al. (1994)
Comparison of tests for glycated haemoglobin and fasting and two hour plasma glucose concentrations as diagnostic methods for diabetes. BMJ 308: 13231328.

35. Cheng Y, Gregg E, Geiss L, Imperatore G, Williams D, et al. (2009) Association of $\mathrm{A} 1 \mathrm{C}$ and Fasting Plasma Glucose Levels With Diabetic Retinopathy Prevalence in the U.S. Population: Implications for diabetes diagnostic thresholds. Diabetes Care 32: 2027-2032.

36. Diabetes Prevention Program Research Group (2002) Reduction in the Incidence of Type 2 Diabetes with Lifestyle Intervention or Metformin. N Eng J Med 346: 393-403.

37. Robinson TW, Freedman BI (2013) Assessing glycemic control in diabetic patients with severe nephropathy. J Ren Nutr 23: 199-202.

38. Blendea M, Thompson M, Malkani S (2010) Diabetes and chronic liver disease: Etiology and pitfalls in monitoring. Clinical Diabetes. 28: 139-144. 